\section{Remission or low disease activity as a target in systemic lupus erythematosus}

We read the report by Zen $e t a l^{1}$ on the impact of lupus low disease activity state (LLDAS) on damage accrual with great interest and would like to congratulate the authors on their work. In this single-centre Caucasian cohort, followed for 7 years, only 38 of their 293 patients (11.3\%) failed to achieve LLDAS for at least 1 year; moreover, of the 255 patients who achieved LLDAS for at least 1 year, $246(96.5 \%)$ also satisfied the definition of remission for the same length of time. And, in 214 (83.9\%) patients, the duration of remission was the same as that of LLDAS. Being in LLDAS for at least 2 years was associated with a reduced risk of damage; but, when remission was included in the multivariable model, remission for at least 2 years was associated with a reduced risk of damage whereas LLDAS was not. Based on these findings, the authors suggest that the effects of LLDAS could be overlapping with those of remission. However, the prevalence of systemic lupus erythematosus (SLE) in non-Caucasian populations is higher and the disease is more severe with patients having, in general, less favourable outcomes; this limits the applicability of Zen et al's results to patients with different characteristics. In fact, our previously published data from the multiethnic, multinational inception Latin American cohort ${ }^{2}$ differs quite a bit from Zen et al's data ${ }^{\mathrm{i}}$. Remission was a relatively rare event with only 273 of 1350 patients (20.2\%) achieving it at least once during their follow-up, and another 192 patients (14.2\%) achieving low disease activity state (LDAS) while 885 (65.6\%) did not achieve either status, with a follow-up of 2.4 years. Since we have a larger number of patients with pure LDAS, it was possible to evaluate the real impact of this status on SLE prognosis. Additionally, since we evaluated these statuses as intervals, we could independently ascertain the impact of remission and LDAS; we found that both statuses were protective of new damage occurrence whereas remission was protective of severe new damage, defined as an increase of at least 3 points in the Systemyc Lupus International Collaborating Clinics/American College of Rheumatology (SLICC/ACR) Damage Index. Moreover, remission and LDAS were protective of both, new and severe new damage excluding those items clearly related to glucocorticoid use suggesting that the effect of LDAS and remission on damage accrual is primarily related to the level of disease activity. Although the definitions of LLDAS and LDAS used by Zen $e$ al and by us are not exactly the same, they nevertheless do not explain by themselves the differences between our publications (both definitions required a Systemic Lupus Erythematosus Disease Activity Index $($ SLEDAI) $\leq 4$, and similar treatment; the definition used by Zen

${ }^{\mathrm{i}}$ Our data were not cited by Zen et al as the dates of both the publications, theirs and ours, were quite close in time. et al included no new lupus disease activity compared with the previous assessment, Physician Global Assessment $\leq 1$ which ours did not require).

Studies from other countries have reported an incidence of remission and LLDAS more comparable to our's than to Zen et al's suggesting than in disadvantaged SLE populations, LLDAS may be an alternative, yet not the ideal, treatment target. ${ }^{3}$

Manuel Francisco Ugarte-Gil, ${ }^{1,2}$ Daniel Wojdyla, ${ }^{3}$ Guillermo J Pons-Estel, ${ }^{4}$ Bernardo A Pons-Estel, ${ }^{5}$ Graciela S Alarcón, ${ }^{6}$ on behalf of GLADEL

${ }^{1}$ Department of Rheumatology, Hospital Guillermo Almenara Irigoyen, EsSalud, Lima, Peru

${ }^{2}$ School of Medicine, Universidad Científica del Sur, Lima, Peru

${ }^{3}$ School of Medicine, Universidad Nacional de Rosario, Rosario, Argentina

${ }^{4}$ Department of Autoimmune Diseases, Hospital Clinic, Barcelona, Spain

${ }^{5}$ Department of Rheumatology, Centro Regional de Enfermedades Autoinmunes y Reumáticas (CREAR), Sanatorio Parque, Rosario, Argentina

${ }^{6}$ Department of Medicine, Division of Clinical Immunology and Rheumatology, School of Medicine, The University of Alabama at Birmingham, Birmingham, Alabama, USA

Correspondence to Manuel Francisco Ugarte-Gil, Department of Rheumatology, Hospital Guillermo Almenara Irigoyen, EsSalud, Lima 33, Peru;

manuel_ugarte@yahoo.com

Contributors All authors were involved in drafting or critically revising this manuscript for important intellectual content, and all authors approved the final version to be published.

Competing interests None declared.

Provenance and peer review Not commissioned; internally peer reviewed.

(c) Article author(s) (or their employer(s) unless otherwise stated in the text of the article) 2019. All rights reserved. No commercial use is permitted unless otherwise expressly granted.

\section{Check for updates}

To cite Ugarte-Gil MF, Wojdyla D, Pons-Estel GJ, et al. Ann Rheum Dis 2019;78:e3.

Received 19 December 2017

Accepted 27 December 2017

Published Online First 8 January 2018

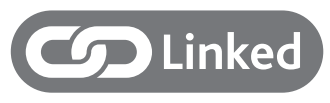

- http://dx.doi.org/10.1136/annrheumdis-2017-212911

Ann Rheum Dis 2019;78:e3. doi:10.1136/annrheumdis-2017-212876

REFERENCES

1 Zen M, laccarino L, Gatto M, et al. Lupus low disease activity state is associated with a decrease in damage progression in Caucasian patients with SLE, but overlaps with remission. Ann Rheum Dis 2018;77:104-10.

2 Ugarte-Gil MF, Wojdyla D, Pons-Estel GJ, et al. Remission and Low Disease Activity Status (LDAS) protect lupus patients from damage occurrence: data from a multiethnic, multinational Latin American Lupus Cohort (GLADEL). Ann Rheum Dis 2017;76:2071-4.

3 Ugarte-Gil MF, Burgos PI, Alarcón GS. Treat to target in systemic lupus erythematosus: a commentary. Clin Rheumatol 2016;35:1903-7. 